\title{
Momentary Engagement as a \\ Complex Dynamic System
}

\section{Authors}

Jennifer E. Symonds ${ }^{1}$

Avi Kaplan ${ }^{2}$

Katja Upadyaya $^{3}$

Katariina Salmela Aro $^{3,4}$

Benjamin M. Torsney ${ }^{2}$

Ellen Skinner ${ }^{5}$

Jacquelynne S. Eccles ${ }^{6,7}$

1. University College Dublin, School of Education, Dublin, Ireland jennifer.symonds@ucd.ie

Corresponding author

2. Temple University, College of Education, Philadelphia, United States akaplan@temple.edu, btorsney@temple.edu

3. University of Helsinki, Faculty of Educational Sciences, Helsinki, Finland katja.upadyaya@gmail.com; katariina.salmela-aro@helsinki.fi

4. ETH Zürich, Collegium Helveticum, Zürich, Switzerland

5. Portland State University, Department of Psychology, Portland, United States skinnere@pdx.edu

6. University of California, Irvine, School of Education, United States jseccles@uci.edu

7. Australian Catholic University, Institute of Positive Psychology, Sydney, Australia

\section{Please reference this pre-print as}

Symonds, J. E.; Kaplan, A.; Upadyaya, K.; Salmela-Aro, K.; Torsney, B.; Skinner, E. \& Eccles,

J. S. (2021) Momentary Engagement as a Complex Dynamic System. PsyArXiv. doi:

10.31234/osf.io/fuy7p. 


\begin{abstract}
We provide a conceptualization of individual people's engagement in tasks as a momentary, situated, and embodied psychological-behavioral experience. We describe how momentary engagement is a complex dynamic system comprising parts (emotion, motivation, mental action, and physical action), structure (coactions between parts) and process (how parts and the whole develop through a sequence of engagement triggers and non-linear action). Momentary engagement can be studied at the microlevel grain sizes of agent (an individual person), task (e.g., video gaming) and time (across seconds and minutes), providing a contrast to research on other forms of engagement occurring at higher level grain sizes (e.g., the participation of a large group of students in schooling across months and years). We overview methodologies for researching momentary engagement complexity, emergence and dynamics; and end with a call for more research on non-linear psychological processes.
\end{abstract}

\title{
Keywords
}

Momentary engagement, engagement, dynamic systems, motivation, student engagement 


\section{Momentary Engagement as a Complex Dynamic System}

The concept of engagement is used to study individuals' involvement in diverse activities such as sports, studying, working, and computer gaming (Andrews \& Bradbury, 2020; Bakker \& Albrecht, 2018; Wang \& Hofkens, 2019). The essential role of engagement in the formation of human competencies (Howard-Jones et al., 2018) has granted it the status of a "holy grail" for researchers interested in learning and development (Sinatra et al., 2015, p.1). However, despite its importance, a consensual science of engagement has been slow to form, with engagement described as "one of the most widely misused and over-generalized constructs found in the educational, learning, instructional, and psychological sciences" (Azevedo, 2015, p. 84).

There are numerous reasons for this slow scientific progress in understanding engagement. One is the lack of theoretical clarity when researching engagement at very different units-of-analysis, conceptualized as levels (Connell \& Wellborn, 1991), or grain sizes, (Sinatra et al., 2015). To illustrate: the notion of engagement has been used to examine a person's activity at the micro-level of agent, task, and time (such as an individual repeatedly throwing a ball to another person as part of a sports' exercise) and at the macro-level of agent, task, and time (e.g., the participation of a large group of students in school-based education across adolescence). Another source of confusion has arisen from the diverse ways in which engagement is defined as a construct. A core conceptual premise in educational psychology is that engagement is multidimensional, comprising emotional, cognitive, and behavioral components (Fredericks, Blumenfeld \& Paris, 2004; Sinatra et al., 2015). But researchers have not agreed on the internal components of engagement not on how they dynamically interrelate (Authors, 2020). The variety of conceptualizations of engagement has prompted calls for new integrative models of engagement to guide research and practice (Azevedo, 2015; Sinatra et al., 2015). 
In this essay, we respond to the call for greater conceptual clarity by applying the Complex Dynamic Systems (CDS) perspective to our conceptualization of engagement occurring at the microlevel grain size of agent (i.e., an individual), task (i.e., learning about climate change), and time (i.e., across seconds and minutes). We term this type of engagement 'momentary engagement', in line with D'Mello et al.'s description of engagement occurring across momentary time (2017). Studies on momentary engagement in education are in their infancy as identified by a recent scoping review (Authors, 2021). Furthermore, momentary engagement has not been formally defined conceptually; with consideration of how activity involvement proceeds dynamically across microlevel time scales. Instead, researchers are applying the construct of engagement as it has been defined for use in cross-sectional attitudinal research at more macro-levels of experience (such as enjoying work). We identify this lack of targeted, formal definition of momentary engagement as a significant issue for researchers interested in humans' lived experience of activities. Defining engagement at the microlevel is critical for understanding how broader patterns of behavior emerge out of momentary experiences.

By applying the CDS perspective to momentary engagement, we offer researchers an integrative ontology for specifying the components of engagement, and the internal dynamic architecture and temporal emergence of the engagement system (Bar-Yam, 1997). Increasingly, the CDS approach is used for conceptualizing dynamic, contextualized, and nonlinear social and psychological phenomena, such as cognition and learning (Hiver et al., 2021; Jacobson et al., 2016), emotion (Nogueiras et al., 2017), psychological development (Witherington, 2015), motivation (Kaplan et al., 2012), identity (Kaplan \& Garner, 2017), and education (Jacobson et 
al., 2019; Koopmans, 2020). This has provided a strong basis for extending the CDS perspective to individual people's momentary engagement in activities.

Although this essay draws primarily on research on engagement in educational activities, owing to our background as educational psychologists, our perspective of momentary engagement can be applied to any specific activity occurring across momentary time (e.g., engagement in playing a computer game, working in teams on problem solving, musical or sports performance, socializing children through discursive interactions, and creating different types of artefacts such as this essay). We begin by defining momentary engagement and reviewing current conceptualizations of engagement in the literature. We then describe the CDS perspective and apply it to momentary engagement. We end the essay by offering suggestions for empirical research on momentary engagement using qualitative and quantitative methods.

\section{Momentary Engagement}

In educational psychology, the concept of engagement began moving to the forefront of researchers' attention in the early 1990s when the field became rich with advances in understanding people's motivation and regulation. These conceptual advances include the expectancy-value model of motivation (e.g., Eccles et al., 1983), the motivational role of psychological need satisfaction (e.g., Connell \& Wellborn, 1991; Skinner \& Belmont, 1993), and the dual-processing model of self-regulation (e.g., Carver \& Scheier, 2002). These perspectives underpinned a wave of empirical research focusing on explaining individuals' valuation of and participation in specific activities: leading to a seminal review that consolidated the outcome phenomenon into a multidimensional concept of engagement (Fredricks, Blumenfeld, \& Paris 2004). 
The recently consolidated field of engagement research has so far focused on people's involvement in complex activities that are sustained over longer time periods such as schooling, and involvement in shorter term activities such as solving a mathematics problem or participating in a lesson. We put forward that these different levels (Connell \& Wellborn, 1991) or grain sizes (Sinatra et al., 2015) of engagement can be further refined into grain sizes of agent, task, and time (Figure 1), where at the microlevel, individual agents participate in discrete tasks (activities) across the second-by-second, and minute-by-minute, pace of momentary time (D'Mello et al., 2017). In this essay, we are concerned with providing a formal conceptualization of momentary engagement to complement recent empirical studies (Authors, 2020; 2019). Momentary engagement refers to the process of being actively involved in a task across seconds and minutes. This perspective overlaps with the concept of situational engagement (Lau \& Roeser, 2002) which focuses on engagement emerging out of situated person-environment interactions. Recognizing the overlaps between the perspectives, we use the term momentary engagement for consistency and clarity throughout this essay.

Figure 1.

Engagement grain sizes

\begin{tabular}{|l|l|l|l|}
\hline & Agent & Task & Time \\
\hline Macrolevel & Microlevel & \\
\hline & & & \\
\hline
\end{tabular}


Research on momentary engagement is rapidly intensifying. Our title and abstract search of PsychInfo on the $31^{\text {st }}$ January 2021 using the search string (momentary OR situational OR situated OR “optimal learning moment” or "experience sampling”) AND (engagement) revealed a surge of interest in the 2010s: with the number of records published per decade increasing from 8 (1980s), to 19 (1990s), to 143 (2000s), to 646 (2010s). Despite this rapid growth in the field, there is no synthesis of momentary engagement research; nor a dedicated conceptualization of engagement occurring at the momentary level of agent, task, and time.

In this essay we seek to bring further conceptual rigor to the expanding field of research on momentary engagement by synthesizing previous perspectives into a meta-theory (i.e., a conceptual perspective) that is structured using a CDS worldview. Working at the level of metatheory is appropriate to provide the initial definition of a phenomenon that can later be refined into testable models and theories (Overton, 2015). Drawing on previous engagement research, we build on the notion that engagement is multidimensional (i.e., complex); comprising taskfocused cognition, effort, and positive emotions (Skinner \& Belmont, 1993); and emerging as a momentary state of attention and absorption (Csikszentmihalyi, 2008; Shernoff et al., 2017) that takes the form of engaged behavior. Using specific conceptual tools from CDS, we further this description by identifying the intrapersonal dynamics that give rise to the fluctuating progression of activity involvement across momentary time. Together this integration and extension of views on engagement provides a conceptual advance and the first formal definition of momentary engagement.

\section{Applying a Complex Dynamic Systems Perspective to Momentary Engagement}


The complex dynamics system (CDS) perspective has seen increased application in social science over the past 50 years (Lewis, 2011). It has been successfully applied to refine and extend conceptualizations of psychological phenomena in numerous domains (Guastello et al., 2009). Using the CDS perspective, we can conceptualize psychological, behavioral, and social phenomena (such as momentary engagement, friendships, or identity) as systems that are complex in structure and dynamics. A system's complexity increases when there are more elements comprising the system, when the elements themselves are complex (i.e., each element is also a complex dynamic system), and when there are more links between elements (Hilpert \& Marchand, 2018). The dynamic nature of CDS is created by the interdependence and continuous coaction (Overton, 2015) of the system's elements (Guastello \& Liebovitch, 2009). We have applied several central tenets of the CDS perspective to momentary engagement in line with other authors' extensions of the perspective to social, psychological phenomena. These are holism, systemic elements, complex dynamics, emergence and self-organization, attractor and repeller states, and non-linearity.

\section{Holism}

A central principle of CDS is the non-reductionist nature of the system, meaning that it cannot be disaggregated into entirely independent components. Because the elements of a CDS emerge across time interdependently with each other, the system's behavior can only be understood holistically, and not through examination of its parts as distinct (Overton, 2015; Witherington, 2017). Correspondingly, momentary engagement is not simply the addition of emotional, motivational, cognitive, and behavioral components (e.g., anticipating satisfaction, being curious, valuing the activity, striving to problem solve, and paying attention). Rather, momentary engagement is the integration of these elements into a whole that is qualitatively 
unique at each individual time point. This perspective is often overlooked by studies that focus on segregated engagement components and their associations and do not consider how engagement manifests dynamically across time.

\section{Momentary Engagement Components}

In this essay, we have built on previous conceptualizations of engagement as a multidimensional phenomenon consisting of emotional, cognitive, and behavioral components (e.g., Connell \& Wellborn 1991; Fredricks et al., 2004; Sinatra et al., 2015; Skinner, 2016). We have expanded on these three dimensions by adding motivational phenomena which were missing from previous engagement definitions. Together, the four components provide a framework in which we have clustered specific psychological and behavioral phenomena that interact in the moment to create the broader engagement phenomenon.

It is important to note that we do not consider all instances of those motivational, cognitive, behavioral, and emotional phenomena as constituting momentary engagement. It is true that while engaged in an activity, a person may experience thoughts, emotions, and behaviors that are not necessary for carrying out that activity; for example, daydreaming about something else, or evaluating alternative actions. While these 'sideline' experiences undoubtedly impact the primary engagement experience, in our conceptualization they do not constitute elements of the engagement system itself. Only the psychological and behavioral phenomena that are targeted constituents of the engagement in action are considered. This follows Witherington's observation that "parts and processes are therefore only fully explicable... when considered as being for the sake of that whole" (Witherington, 2017, p. 18). In this section we briefly describe the constituents of momentary engagement.

\section{Motivation}


Motivation is a term that refers to specific cognitive processes "that underlie the energy (vigor, intensity, arousal), purpose (initiation, direction, channeling, choice), and durability (persistence, maintenance, endurance, sustenance)" (Skinner et al., 2008, p. 225) of action. The word motivation is a linguistic tool that should not be confused with being a cognitive process in itself (Murayama, in press). Whether or not motivational cognitive processes are part of momentary engagement depends on whether they are involved in triggering and sustaining engagement as it proceeds across time. The basic motivational processes occurring in momentary engagement are identification of action possibilities, evaluation of these against one's potential to achieve them and the ensuing consequences; and forming and following through on intentions to achieve those action possibilities (Uusberg et al., 2019; Azjen, 2020). For example, you might identify the task of reading this essay, evaluate whether you will finish it against your ability to maintain your interest and the anticipate reward or costs, and form a goal to get half-way through before stopping.

Identification and evaluation of an action possibilities can be triggered by action intentions (such as goals) which can be subliminal and unconsciously activated, or metacognitively designed and employed to direct action (Chen et al., 2021). The standards that action possibilities are evaluated against can be observed such as a time limitation or economic cost. They can also be subjective such as perceived ability to act (Bandura, 2001), perceived behavioral control (Azjen, 2020), attitudes (Van Bavel et al., 2012), and perceived value of the activity (Eccles \& Wigfield, 2020). Imagined consequences of action include emotions (Mellers et al., 1999) such as the satisfaction that comes with satiating epistemic curiosity (the urge to close the gap between the feeling of what is known and the identification of what could be known) (Metcalfe et al., 2020). In turn, further intentions can be generated based on those 
evaluations. Together (with other motivational cognitions - too many to adequately describe here) these cognitive processes encourage the action components of momentary engagement.

\section{Cognitive Action}

This component refers to the cognitive activity necessary for performing the task, such as processing information. Here we distinguish between 'hot' and 'cold' cognitive processes (Pintrich et al., 1993), with the former (i.e., motivation) serving the energization of the latter. Momentary cognitive action comprises a wide set of engaged mental processes, including activating perception, retrieving images from episodic memory, selection, encoding, categorizing, constructing part-whole relationships, mental reasoning (Metzinger, 2017), motor imagery, and planning (Mendelsohn et al., 2014). These cognitive actions reciprocally interact with the brain's capacity for attention; being guided and limited by attention, whilst also directing it (Chun et al., 2012). When converging on the object of engagement (e.g., solving a problem or playing a musical instrument), these cognitive actions can manifest in concentration which is the state of focusing on the task while avoiding distractors (Moran \& Toner, 2018).

\section{Behavior}

The types of behavior inherent in momentary engagement include the motor behavioral movements that the person enacts to create engagement. This can include behaviors such as talking to colleague in a collaborative task, writing down the computation for an algorithm, or performing the movements necessary for a sporting activity. Momentary engagement behaviors can be relaxed or vigorous and comprise discrete actions including postures, gestures, and hand, head and gaze movements that direct attention to and away from stimuli (Sohlberg \& Mateer, 2001). In recent empirical research on momentary engagement, behavior has been operationalized and studied at different grain sizes of time and specificity. Böheim et al. (2020) 
studied the frequency and timing of hand-raising as a discrete type of momentary engagement behavior, and Erikson et al. (2020) and Torsney and Symonds (2019) studied students' on-task behavior (students' behavior visibly oriented towards task participation) proceeding across timed intervals.

\section{Emotions}

The final component of momentary engagement as a CDS is emotion. Emotional experiences, mood, and affect help constitute momentary engagement if they emerge momentarily in response to engagement or are used to motivate engagement. For example, momentary epistemic emotions can arise from an individual's experience of doing the activity such as surprise, curiosity, enjoyment, confusion, anxiety, frustration, and boredom (Metcalfe et al., 2020; Pekrun et al., 2017). Emotions and mood can help energize behavior and direct attention in the moment (Barros et al., 2017), and memories of those emotions that form while the emotions are occurring can be used to anticipate future positive emotions arising from continuing with the activity (Mellers et al., 1999).

\section{Internal Dynamics}

Complex dynamic systems are always changing due to the active interdependencies among their components and due to the embeddedness of the CDS in a continually evolving context (i.e., situatedness). Three main types of coactions in CDS's are where: (1) changes in components impact other components (parts-to-parts coactions), (2) changes in components impact the overall system (parts-to-whole coactions), and (3) changes in the system impacts its components (whole-to-parts coactions) (Overton, 2015). These three types of coactions create respective horizontal, upwards, and downwards influences on the system. The unified process of dynamic upwards and downwards influences which shapes the system is referred to as circular 
causality (Witherington, 2011). Through circular causality, the system and its parts are in a continued state of development.

From a coaction perspective, the components of momentary engagement (motivation, cognitive action, behavior, and emotion) and smaller components within those larger components (e.g., forming goals, effortful striving, imagining, deciding, and feeling happy) can influence and reinforce each other (parts-to-parts coactions), thus sustaining the overarching experience of engagement (parts-to-whole coactions), which, as it continually emerges through time, influences the formation of its parts (whole-to-parts coactions). A simple example is where a person's happiness sustains their motivation in tackling a household chore: and this embodied action generates further emotional reward as the chore is gradually accomplished.

\section{Self-Organization}

The next issue to consider is how the coactions between momentary engagement and its components of emotion, engaged cognition, and engaged behavior, give rise to momentary engagement across time. In this section we discuss self-organization, which is how the system organizes itself into a continued state of emergence.

The self-organization of momentary engagement's dynamics can be unconscious and organismic, where the system organizes itself outside of the individual's awareness (Gestsdottir \& Lerner, 2008), such as becoming unconsciously absorbed in playing a computer game. Organismic self-regulation, although unconscious, can still be goal directed, for example continuing to play the game to satisfy the subconscious goal of obtaining pleasure from the action. The continuation of this 'bottom-up' control process serves to continue the assembly of the system's components to sustain the emergence of the system (Carver \& Scheier, 2002). 
Self-organization can also be conscious, for example intentionally controlling a feeling of frustration using emotional suppression to sustain engagement in a challenging activity. Using conscious 'top-down' control processes (Carver \& Scheier, 2002), people can consciously organize their own internal dynamic systems as authors of their own activity (Witherington, 2017). Top-down control processes can be conceptualized as a form of agency, which has even been conceptualized as a part of engagement in some definitions, for example when a student strives to change the instructional flow to better meet their needs (Reeve \& Tseng, 2011).

Within the momentary engagement dynamic system, bottom-up and top-down control processes act together to sustain engagement. Following Van Bavel and colleagues' (2012) Interative Reprocessing (IR) model, intentional and unconscious processes mutually influence each other to self-organize a dynamic system. For example, intentional goal striving (e.g., trying to finish reading this essay) can influence the conditions for unconscious engaged behavior (e.g., reading the words without thinking about reading) to emerge.

\section{Attractor and Repeller States}

When a CDS self-organizes into a relatively stable pattern across time, this can be conceptualized as an attractor state (e.g., Hilpert \& Marchand, 2018; Hollenstein, 2017). Once the system is in an attractor state, the mutually affirming coactions between components and the system continue and even though the system continues to emerge it manifests as relatively stable. Attractors states are described as "highly "absorbing” states to which the system frequently returns' (Hollenstein, 2007, p. 385). An example of an attractor state in momentary engagement could be complete absorption in gaming or in reading a fiction novel. Attractor states can be represented visually as broad, deep basins that the CDS easily falls into (Hollenstein, 2007). From a self-regulation and motivation perspective, momentary engagement emerges into an 
attractor state when the motivation feedback loop consolidates across time into a pattern of relatively stable internal dynamics: including for example anticipated coactions between specific types of emotion, engaged cognition, and engaged behavior, regular action-action possibility gaps, and frequent experiences of effective gap closure.

In contrast, dynamic systems can also self-organize into repeller states. Repeller states are very difficult for the system to converge into and to remain stable in for longer periods - they can be represented visually as steep peaks that the system might ascend to rarely and decline from rapidly (Hollenstein, 2007). For example, an individual who actively dislikes mathematics and typically becomes frustrated with mathematics problems might on the odd occasion become engrossed in a mathematics task, but typically they would avoid momentarily engaging in mathematics. This illustrates how what can be an attractor state for one individual (e.g., mathematics tasks), can be a repeller state for another individual.

An extreme form of momentary engagement is the attractor state where people enter a state of flow, which is deep absorption in a task (Csikszentmihalyi, 2008). Flow emerges when there is an individual optimal configuration of challenge and skill (Shernoff et al., 2017). In turn, the hypnotic qualities of absorption can lead to a loss of time perception and altered sense of self, both of which reduce people's attention to distractors (Csikszentmihalyi, 2008), sustaining longer and deeper engagement. Flow epitomizes automatic (rather than intentional) circular causation that leads to the emergence of mutually affirming co-actions between components, and between components and the whole. To achieve a flow state, individuals can move from a conscious, top-down regulation of their momentary engagement (e.g., instructing the body to jump up on the surfboard) to a state of unconscious and organismic self-organization (e.g., 
loosing sense of time and body when riding the wave) which is continually motivated by feedback loop dynamics.

\section{Non-Linearity}

Because complex dynamic systems are continually emerging, with components and the whole system changing dynamically in form across time, they are conceived as non-linear (Hilpert \& Marchand, 2018). Non-linearity refers to the rate of change within the system, to the direction of association (or coaction) between the components, and to the pathways between components and the whole. Imagine an individual trying to master a new skill. In a linear system, a positive activating emotion such as excitement (Pekrun et al., 2007) experienced during the activity would always influence the other components of engagement (e.g., enthusiasm for the activity) at regular intervals and to a similar extent. However, experience of positive activating emotions might not always impact enthusiasm for the activity with the same degree of association nor regularity. Although non-linearity can pose technical challenge for researchers, Witherington (2017) notes that to be able to predict this type of complex, irregular functioning, all that might be needed is greater scientific precision.

Our above examples of non-linearity focus on parts-to-parts coactions, but they can also be applied to whole-to-parts and parts-to-whole coactions, such as a minor change in one part (e.g., an employer noting that their employee forgot to bring in their equipment) having a disproportional impact across the system (e.g., a major shift in the employee's sense of selfworth) that is only evident after time has elapsed (van Geert, 2011); or the holistic experience of an optimal learning moment emerging out of the convergence of positive internal dynamics that are set in motion by the interplay between the individual and their environment (Schneider et al., 2016). 
In summary, momentary engagement is individual involvement in an activity that proceeds through complex non-linear psychological and behavioral dynamics occurring across seconds and minutes. Although engagement manifests as nonlinear patterns of psychology and behavior that can involve sudden changes, the system generally strives to retain its integrity through conscious and unconscious self-organization towards attractor states. Next, we discuss how the engagement process unfolds across momentary time.

\section{The Process of Momentary Engagement}

In this section, we describe how momentary engagement can develop across seconds and minutes (D'Mello et al., 2017) as a 'rapid' complex dynamic system, with coactions between internal components and external factors quickly arising and disappearing.

\section{Trigger}

Engaging momentarily in a task necessarily needs a trigger. In their seminal work on attention, agency and consciousness, Norman and Shallice (1986) described how attention can trigger action in a manner that is consciously controlled or automatic. For example, you might notice the messy pile of papers on your desk then deliberately move to tidy them, or you might unconsciously prevent yourself from falling off a cliff by adjusting your footing. In these examples, aspects of the environment have triggered engagement, just as a teacher might give students instructions to complete a new task. Perceptions of future states also commonly act as triggers; for example, setting a task-oriented goal (I want to solve this problem) that energizes motivation to act. Similarly, Renninger and Bachrach (2015) have identified triggers for interest that spark continued engagement in tasks. Even if people transition into engagement automatically, there is a trigger, such as a change in the environment that might not be salient to the individual. 


\section{Action Sequence}

In our conceptualization, the emergence of momentary engagement across seconds and minutes is referred to as the 'action sequence'. During the action sequence, engagement is created by continued, rapid internal dynamics that can proceed in irregular directions and pathways, and at an irregular rate. These internal dynamics converge into the attractor state of momentary engagement through a motivational feedback loop that is consciously and unconsciously self-organized. As engagement proceeds, continual changes in momentary experience (psychological and behavioral) and in the external environment (where engagement is situated) impact on the components and organization of the feedback loop. Individuals can consciously maintain their momentary engagement by reappraising these components to minimize the gap between action and action possibility, or by channeling further energy and resources into closing that gap.

\section{Disengagement}

In the Motivational Theory of Life-Span Development, Heckhausen, Wrosch and Schulz (2010) explained that disengaging from a goal (or an activity) can be adaptive and can signal a readiness to move onto a phase of development that is more productive. Similarly, in momentary engagement, disengagement can be productive, moving the person to a different activity that needs to be attended to; for example, an individual who finished solving one problem moves to attend to the next. Disengagement, i.e., the act of stopping engagement in a task, is different from disaffection, which reflects a broader notion involving lack or loss of motivation, passivity, or disruption that is accompanied by negative emotions (such as boredom, frustration, resentment, or anxiety) (Skinner, 2016). In the momentary engagement process, disengagement can signal a natural ending to action, or be an intermittent state within a longer engagement process that 
occurs as people consciously or unconsciously withdraw their attention from the task at hand.

For example, mind wandering can be an adaptive form of disengagement that allows the momentary engagement system to completely reform — creating a new form of engagement that might be more fit for purpose.

\section{Implications for Assessment and Research}

\section{Researching Momentary Engagement at the Microlevel Grain Size}

The first consideration for researching momentary engagement is to identify the grain sizes of agent, task, and time (Figure 1), that will best address the research question or hypotheses. It may be valuable, depending on the research question, to study momentary engagement as it develops across a brief period for an individual. This type of study would be located at the microlevel of agent, task, and time, for example studying how an individual organizes their work desk in preparation for the next day. A suitable approach is a microgenetic design where data are collected before and after the action sequence of engaging, and intensively throughout the action sequence; and are analyzed intensively in relation to each other to identify how change in momentary engagement occurs (e.g., Lavelli et al., 2005).

It is also possible to study momentary engagement by increasing the grain size of agent to the macrolevel of a large group of individuals, while keeping the grain size of time and task at the microlevel. An example is systematically observing individual behavior in a single, standardized task occurring across a timed interval, and repeating these observations in a larger sample of multiple individuals (Authors 2020; Authors 2019).

\section{Researching Momentary Engagement as a Complex Dynamic System}

Here we give several suggestions for future research into momentary engagement as a dynamic system, using Hilpert and Marchand's (2018) framework of studying a dynamic 
system's complexity (the need to capture the system's parts and their relations); dynamism (explored by studying the parts and the whole longitudinally); and emergence (capturing the emergence of the system as a holistic contextualized phenomenon). These suggestions are not exhaustive: each is selected to exemplify a particular approach that can be used to test many different assumptions about momentary engagement as a dynamic system.

\section{Researching Complexity}

Although we have proposed that momentary engagement is made of the components of emotion, engaged cognition, and engaged behavior, the specific qualities of each components might manifest differently depending on the individual, task, time, and context. For example, which emotions surface during a specific task? Which forms of engaged cognition (e.g., positive attitudes towards the task, or strategic information processing) are present and salient? Researchers can test hypotheses about the qualities of individual components based on what they know about the task, the sample, and the context. For example, do the qualities of components differ across the conditions of watching a film versus studying for an examination?

\section{Researching Dynamics}

Researchers may also wish to test how the parts of momentary engagement influence each other (parts-to-parts coactions), influence the system (parts-to-whole coactions), or are influenced by the system (whole-to-parts coactions) (Witherington, 2011). Careful examination of each type of coaction is required, and studies could focus on one or several of the coaction types.

To test parts-to-parts coactions within a single time point, researchers could use configural frequency analysis (CFA) (e.g., von Eye \& Mun, 2016). CFA is a person-oriented statistical method where all possible overlaps between categories (e.g., shame overlapping with 
inattention, or pride overlapping with inattention), known as 'cross-classifications' or 'profiles' (von Eye \& Mun, 2016) are tested to identify which occur more frequently ('types') or less frequently ('anti-types') than can be expected using probability modelling.

Researchers can also test longitudinal associations between parts using CFA (von Eye \& Mun, 2016), with specific hypotheses in mind. For example, researchers might test whether individuals tend to move into more or less attentive states, based on experiencing stronger or weaker amounts of a specific measured emotion such as interest. This could help identify whether experiences of strong interest can trigger attention from a previously inattentive state, and vice versa.

Longitudinal associations between parts can also be examined using variable-oriented methods, such as bivariate multilevel autoregressive modeling (Schuurman et al., 2016). This technique models the lagged associations between multiple variables, with coefficients standardized within persons, to identify which variables are more central in the process across time (Schuurman et al., 2016).

A sophisticated method of studying coactions between parts developed especially for research on momentary engagement is the Advanced, Analytic, Automated (AAA) approach (D'Mello et al., 2017). A core assumption of the AAA approach is that inner emotional and psychological states (e.g., frustration, problem solving) are experienced at multiple levels (e.g., neurobiological, physiological, metacognitive, subjective) (D’Mello et al., 2017, p. 107). Only some levels (e.g., behavior) can be measured by external technologies such as machine sensors, whereas others (e.g., subjective feelings) are directly accessible only to the individual subject, who must represent these to the researchers. In AAA, machine learning is used to infer mental states, by working a set of observed 'signals' (e.g., facial expression) into estimations of specific 
mental states (e.g., interest), validated by human judgements in the initial phases of the process. This method yields information on the coaction of observable and unobservable states during the engagement process.

\section{Researching Emergence}

Researchers can study the continued emergence of the momentary engagement system, using methods well suited for identifying circular causality (Witherington, 2011) i.e., parts-towhole, and whole-to-parts coactions. They might wish to test hypotheses about at what point during a measured sequence, or in relation to which overlaps between variables, momentary engagement moves into specific attractor and repeller states. For example, researchers could use psychological network analysis (e.g., Bruun, Lindahl \& Linder, 2018) to identify how engagement components cluster together to create specific forms of engagement, within time points and individuals, and across individuals and time.

State space grids (e.g., Hollenstein, 2007; Meinecke et al., 2019) are another option for identifying attractor states. State space grids are based on the perspective that dynamic systems visit specific states (e.g., interested but off task) and that only one state is possible during any given moment (Hollenstein, 2007). With a state space grid, researchers map the components (e.g., interest / disinterest) of Variable 1 on the $\mathrm{x}$ axis, and the components of Variable 2 (e.g., on task, off task) on the y axis. Both variables are measured at the same, multiple time points. The coaction between variables (e.g., Variable $1=$ interest and Variable $2=$ off task) at each time point is mapped sequentially onto the grid, creating a temporal density map of how long specific states (coactions) occur for, and in what order. This can be used to identify attractor states, where the dynamic system revisits a specific state with higher frequency across time, and repeller states that the system has more difficulty converging around. It can also be used to identify phase 
transitions, where the system converges around a new attractor state, after key events or time periods have occurred (Hollenstein, 2007). Researchers can also use this method to test the impact of external antecedents and covariates on momentary engagement (e.g., a change in environment that impacts the flow of engagement).

\section{Application of Computerized Models}

Once researchers have accumulated enough knowledge to make viable predictions about how momentary engagement operates as a dynamic system, they might wish to build computerized models that can simulate how the system will function under certain conditions. System dynamics models could be used to identify feedback loops (that reinforce the stability of the system) that emerge and persist across a period of momentary engagement (Read et al., 2020). These computerized models advance on structural equation models by accounting for feedback loops within the parts (or 'stocks') of the system, and for the time delay in how individuals move from one feedback loop to the next (Howard \& Thompson, 2016).

Another example is the agent-based model, where the model is built 'ground up' from recurring information collected from individuals (Read et al., 2020). An excellent example of an agent-based model is the AAA method (D'Mello et al., 2017) described earlier, where the programmers built a computerized model based on what humans described as the real system of momentary student engagement, used the model to simulate the system based on machine sensor data, and corroborated the model based on human validation of the results while the model was in its initial design phase. Both system dynamics and agent-based models can be used to test hypotheses about how momentary student engagement forms and functions, with the former model testing deductive models of the dynamic system, and the latter model taking an inductive approach to describe the system. 


\section{Conclusion}

Our conceptualization of momentary engagement as a complex dynamic system aims to add clarity and specificity to the field of engagement research (Azevedo, 2015). As other dynamic systems researchers have voiced, the necessary complexity of any dynamic system may deter some researchers from investigating it in detail, because they prefer to limit their activity to tried and tested methods that are readily welcomed by journal editors and reviewers (van Geert, 2011; Lewis, 2011). However, the research topics posed above indicate how a CDS perspective on momentary engagement can advance our understanding of how individuals engage in specific tasks, which in turn will help us progress knowledge on how students engage in classrooms and schools.

Understanding momentary engagement as a complex dynamic system requires a paradigm shift, a meaningful reconceptualization of existing data in our field, and a continued push for new methods for the collection and analysis of data. It will require time and the support of journal editors and reviewers who look open-mindedly on research that takes the risk of collecting and analyzing these data, but we believe that this is necessary for challenging the status quo in engagement theory and research. As stated by Lewis (2011, p. 4), "Dynamic thinkers should be the first to recognize that complex systems - including the conceptual habits of a scientific subdiscipline - resist change until they can no longer absorb perturbations." We hope that this essay might be a significant step in this direction. 


\section{References}

Andrews, S., \& Bradbury, R. E. (2020). Fiero and flow in online competitive gaming: The gaming engagement framework. International Journal of Gaming and Computer-Mediated Simulations, 12(1), 1-15. https://doi.org/10.4018/IJGCMS.2020010102

Azevedo, R. (2015). Defining and measuring engagement and learning in science: conceptual, theoretical, methodological, and analytical issues. Educational Psychologist, 50(1), 84-94. https://doi.org/10.1080/00461520.2015.1004069

Ajzen, I. (2020). The theory of planned behavior: Frequently asked questions. Human Behavior and Emerging Technologies, 2(4), 314-324. https://doi.org/10.1002/hbe2.195

Bakker, A. B., \& Albrecht, S. (2018). Work engagement: current trends. Career Development International, 23(1), 4-11. https://doi.org/10.1108/CDI-11-2017-0207

Barros, P., Parisi, G. I., Weber, C., \& Wermter, S. (2017). Emotion-modulated attention improves expression recognition: A deep learning model. Neurocomputing, 253, 104-114. https://doi.org/10.1016/j.neucom.2017.01.096

Böheim, R., Knogler, M., Kosel, C., \& Seidel, T. (2020). Exploring student hand-raising across two school subjects using mixed methods: An investigation of an everyday classroom behavior from a motivational perspective. Learning and Instruction, 65, 101250. https://doi.org/10.1016/j.learninstruc.2019.101250

Bruun, J., Lindahl, M., \& Linder, C. (2018). Network analysis and qualitative discourse analysis of a classroom group discussion. International Journal of Research \& Method in Education, 1-23. https://doi.org/10.1080/1743727X.2018.1496414 
Carver, C. S., \& Scheier, M. F. (2002). Control processes and self-organization as complementary principles underlying behavior. Personality and Social Psychology Review, 6(4), 304-315. doi: https://doi.org/10.1207/s15327957pspr0604_05

Chen, X., Latham, G. P., Piccolo, R. F., \& Itzchakov, G. (2021). An enumerative review and a meta-analysis of primed goal effects on organizational behavior. Applied Psychology, 70(1), 216-253. https://doi.org/10.1111/apps.12239

Chun, M. M., Golomb, J. D., \& Turk-Browne, N. B. (2011). A taxonomy of external and internal attention. Annual review of psychology, 62, 73-101. https://doi.org/10.1146/annurev.psych.093008.100427

Connell, J. P., \& Wellborn, J. G. (1991). Competence, autonomy, and relatedness: A motivational analysis of self-system processes. In M. R. Gunnar \& L. A. Sroufe (Eds.), Self Processes and Development (pp. 43-77): Lawrence Erlbaum Associates, Inc, Hillsdale, NJ.

Csikszentmihalyi, M. (2008). Flow: the psychology of optimal experience. Harper Perennial.

D'Mello, S., Dieterle, E., \& Duckworth, A. (2017). Advanced, Analytic, Automated (AAA) measurement of engagement during learning. Educational Psychologist, 52(2), 104-123. https://doi.org/10.1080/00461520.2017.1281747

Eccles, J., Adler, T., Futterman, R., Goff, S., Kaczala, C., Meece, J., \& Midgley, C. (1983). Expectancies, values and academic behavior. In J. T. Spence (Ed.), Achievement and achievement motives: psychological and sociological approaches (pp. 75-146). W. H. Freeman.

Eccles, J. S., \& Wigfield, A. (2020). From expectancy-value theory to situated expectancy-value theory: A developmental, social cognitive, and sociocultural perspective on motivation. 
Contemporary Educational Psychology, 61, 101859.

https://doi.org/10.1016/j.cedpsych.2020.101859

Fredricks, J., Blumenfeld, P., \& Paris, A. (2004). School engagement: potential of the concept, state of the evidence. Review of Educational Research, 74(1), 59-109. https://www.jstor.org/stable/3516061

Guastello, S. J., Koopmans, M., \& Pincus, D. (Eds.). (2009). Chaos and complexity in psychology: The theory of nonlinear dynamical systems. Cambridge University Press.

Guastello, S. J., \& Liebovitch, L. S. (2009). Introduction to nonlinear dynamics and complexity. In S. J. Guastello, M. Koopmans, \& D. Pincus (Eds.), Chaos and complexity in psychology: The theory of nonlinear dynamical systems (pp. 1-40). Cambridge University Press.

Heckhausen, J., Wrosch, C., \& Schulz, R. (2010). A motivational theory of life-span development. Psychological Review, 117(1), 32-60. https://doi.org/10.1037/a0017668

Hilpert, J. C., \& Marchand, G. C. (2018). Complex systems research in educational psychology: Aligning theory and method. Educational Psychologist, 53(3), 185-202. https://doi.org/10.1080/00461520.2018.1469411

Hiver, P., Al-Hoorie, A. H., \& Larsen-Freeman, D. (2021). Toward a transdisciplinary integration of research purposes and methods for Complex Dynamic Systems Theory: Beyond the quantitative-qualitative divide. International Review of Applied Linguistics in Language Teaching. https://doi.org/10.1515/iral-2021-0022

Hollenstein, T. (2007). State space grids: Analyzing dynamics across development. International Journal of Behavioral Development, 31(4), 384-396.

https://doi.org/10.1177/0165025407077765 
Howard, S. K., \& Thompson, K. (2016). Seeing the system: Dynamics and complexity of technology integration in secondary schools. Education and Information Technologies, 21(6), 1877-1894. https://doi.org/10.1007/s10639-015-9424-2

Howard-Jones, P., Ioannou, K., Bailey, R., Prior, J., Hui Yau, S., \& Jay, T. (2018). Applying the science of learning in the classroom. Impact: Journal of the Chartered College of Teaching, 1(2), https://impact.chartered.college/article/howard-jones-applying-sciencelearning-classroom/

Kaplan, A., \& Garner, J. K. (2017). A complex dynamic systems perspective on identity and its development: The dynamic systems model of role identity. Developmental Psychology, 53(11), 2036-2051. https://doi.org/10.1037/dev0000339

Koopmans, M. (2020). Education is a complex dynamical system: Challenges for research. The Journal of Experimental Education, 88(3), 358-374. doi: 10.1080/00220973.2019.1566199

Jacobson, M. J., Kapur, M., \& Reimann, P. (2016). Conceptualizing debates in learning and educational research: Toward a complex systems conceptual framework of learning. Educational Psychologist, 51(2), 210-218. https://doi.org/10.1080/00461520.2016.1166963

Jacobson, M. J. (2020). Complexity conceptual perspectives for research about educational complex systems. The Journal of Experimental Education, 88(3), 375-381. https://doi.org/10.1080/00220973.2019.1652138

Lau, S., \& Roeser, R. W. (2002). Cognitive abilities and motivational processes in high school students' situational engagement and achievement in science. Educational Assessment, 8(2), 139-162. https://doi.org/10.1207/S15326977EA0802_04 
Lewis, M. D. (2011). Dynamic systems approaches: Cool enough? Hot enough? Child Development Perspectives, 5(4), 279-285. https://doi.org/10.1111/j.1750$\underline{8606.2011 .00190 . x}$

Meinecke, A. L., Hemshorn de Sanchez, C. S., Lehmann-Willenbrock, N., \& Buengeler, C. (2019). Using state space grids for modeling temporal team dynamics. Frontiers in Psychology, 10(863). https://doi.org/10.3389/fpsyg.2019.00863

Mellers, B., Schwartz, A., \& Ritov, I. (1999). Emotion-based choice. Journal of Experimental Psychology: General, 128(3), 332-345. https://doi.org/10.1037/0096-3445.128.3.332

Mendelsohn, A., Pine, A., \& Schiller, D. (2014). Between thoughts and actions: motivationally salient cues invigorate mental action in the human brain. Neuron, 81(1), 207-217. https://doi.org/10.1016/j.neuron.2013.10.019

Metzinger, T. (2017). The problem of mental action - predictive control without sensory sheets. In T. Metzinger \& W. Wiese (Eds.), Philosophy and predictive processing. MIND Group. Moran, A., \& Toner, J. (2018). Attentional processes in sport and performance. In Oxford Research Encyclopaedia of Psychology. Oxford: Oxford University Press.

Murayama, K. (in press). Motivation resides only in our language, not in our mental processes. In M. Bong, S. Kim \& J. Reeve (Eds.), Motivation science: Controversies and insights: Oxford University Press.

Nogueiras, G., Kunnen, E. S., \& Iborra, A. (2017). Managing contextual complexity in an experiential learning course: A dynamic systems approach through the identification of turning points in students' emotional trajectories. Frontiers in Psychology, 8(667). https://doi.org/10.3389/fpsyg.2017.00667 
Norman, D. A., \& Shallice, T. (1986). Attention to action: Willed and automatic control of behavior. In R. J. Davidson, G. E. Schwartz, \& D. Shapiro (Eds.), Consciousness and selfregulation: Advances in research and theory. Plenum Press.

Overton, W. F. (2015). Processes, relations, and relational developmental systems. In R. M. Lerner (Ed.), Handbook of child psychology and developmental science (pp. 9-62). Wiley.

Pekrun, R., Frenzel, A. C., Goetz, T., \& Perry, R. P. (2007). The control-value theory of achievement emotions: An integrative approach to emotions in education. In P. A. Schutz \& R. Pekrun (Eds.), Emotion in Education (pp. 13-36). Academic Press.

Pekrun, R., Vogl, E., Muis, K. R., \& Sinatra, G. M. (2017). Measuring emotions during epistemic activities: the Epistemically-Related Emotion Scales. Cognition and Emotion, 31(6), 1268-1276. https://doi.org/10.1080/02699931.2016.1204989

Pintrich, P. R., Marx, R. W., \& Boyle, R. A. (1993). Beyond cold conceptual change: The role of motivational beliefs and classroom contextual factors in the process of conceptual change. Review of Educational Research, 63(2), 167-199. https://doi.org/10.3102/00346543063002167 F

Read, G. J. M., Salmon, P. M., Thompson, J., \& McClure, R. (2020). Simulating the behaviour of complex systems: Computational modelling in ergonomics. Ergonomics, 1-14. https://doi.org/10.1080/00140139.2020.1786263

Reeve, J., \& Tseng, M. . (2011). Agency as a fourth aspect of student engagement during learning activities. Contemporary Educational Psychology, 36(1), 257-267. https://doi.org/10.1016/j.cedpsych.2011.05.002 
Renninger, K. A., \& Bachrach, J. E. (2015). Studying triggers for interest and engagement using observational methods. Educational Psychologist, 50(1), 58-69. https://doi.org/10.1080/00461520.2014.999920

Schmidt, J. A., Rosenberg, J. M., \& Beymer, P. N. (2018). A person-in-context approach to student engagement in science: Examining learning activities and choice. Journal of Research in Science Teaching, 55(1), 19-43. https://doi.org/10.1002/tea.21409

Schneider, B., Krajcik, J., Lavonen, J., Salmela-Aro, K., Broda, M., Spicer, J. Bruner, J., Moeller, J., Linnansaari, J., Juuti, K. \& Viljaranta, J. (2016). Investigating optimal learning moments in U.S. and Finnish science classes. Journal of Research in Science Teaching, 53(3), 400-421. https://doi.org/10.1002/tea.21306

Schuurman, N. K., Ferrer, E., de Boer-Sonnenschein, M., \& Hamaker, E. L. (2016). How to compare cross-lagged associations in a multilevel autoregressive model. Psychological Methods, 21(2), 206-221. https://doi.org/10.1037/met0000062

Shernoff, D. J., Ruzek, E. A., Sannella, A. J., Schorr, R. Y., Sanchez-Wall, L., \& Bressler, D. M. (2017). Student engagement as a general factor of classroom experience: associations with student practices and educational outcomes in a university gateway course. Frontiers in Psychology, 8, 994. https://doi.org/10.3389/fpsyg.2017.00994

Sinatra, G. M., Heddy, B. C., \& Lombardi, D. (2015). The challenges of defining and measuring student engagement in science. Educational Psychologist, 50(1), 1-13. https://doi.org/10.1080/00461520.2014.1002924

Skinner, E. A. (2016). Engagement and disaffection as central to processes of motivational resilience development. In K. Wentzel \& D. Miele (Eds.), Handbook of motivation at school, 2nd ed (pp. 145-168). Erlbaum. 
Skinner, E. A., \& Belmont, M. J. (1993). Motivation in the classroom: Reciprocal effects of teacher behavior and student engagement across the school year. Journal of Educational Psychology, 85(4), 571-581. https://doi.org/10.1037/0022-0663.85.4.571

Skinner, E. A., Marchand, G., Furrer, C., \& Kindermann, T. (2008). Engagement and disaffection in the classroom: part of a larger motivational dynamic? Journal of Educational Psychology, 100(4), 765-781. https://doi.org/10.1037/a0012840

Skinner, E. A., \& Pitzer, J. R. (2012). Developmental dynamics of student engagement, coping and everyday resilience. In S. L. Christenson, A. L. Reschly \& C. Wylie (Eds.), Handbook of research on school engagement (pp. 21-44). Springer.

Sohlberg, M. M., \& Mateer, C. A. (2001). Improving attention and managing attentional problems. Annals of the New York Academy of Sciences, 931(1), 359-375. https://doi.org/10.1111/j.1749-6632.2001.tb05790.x

Symonds, J. E., Schreiber, J. B., \& Torsney, B. M. (2020). Silver linings and storm clouds: Divergent profiles of momentary engagement emerge in response to the same task. Journal of Educational Psychology, Online first. https://doi.org/10.31219/osf.io/nh8zk

Torsney, B. M., \& Symonds, J. E. (2019). The professional student program for educational resilience: Enhancing momentary engagement in classwork. The Journal of Educational Research, 112(6), 676-692. https://doi.org/10.1080/00220671.2019.1687414

Uusberg, A., Suri, G., Dweck, C. S., \& Gross, J. J. (2019). Motivation: A valuation systems perspective. In M. Neta \& I. J. Hass (Eds.), Emotion in the Mind and Body (pp. 161-192): Springer Nature Switzerland. 
Van Bavel, J. J., Jenny Xiao, Y., \& Cunningham, W. A. (2012). Evaluation is a dynamic process: Moving beyond dual system models. Social and Personality Psychology Compass, 6(6), 438-454. https://doi.org/10.1111/j.1751-9004.2012.00438.x

van Geert, P. (2011). The contribution of complex dynamic systems to development. Child Development Perspectives, 5(4), 273-278. https://doi.org/10.1111/j.1750$\underline{8606.2011 .00197 . x}$

von Eye, A., \& Mun, E.-Y. (2016). Configural frequency analysis for research on developmental processes. In D. Cicchetti (Ed.), Developmental Psychopathology (pp. 866-921): John Wiley \& Sons, Inc.

Wang, M.-T., \& Hofkens, T. L. (2019). Beyond classroom academics: a school-wide and multicontextual perspective on student engagement in school. Adolescent Research Review. https://doi.org/10.1007/s40894-019-00115-z

Witherington, D. C. (2011). Taking emergence seriously: the centrality of circular causality for dynamic systems approaches to development. Human Development, 54(2), 66-92 https://doi.org/10.1159/000326814

Witherington, D. C. (2017). The explanatory significance of wholes: How exclusive reliance on antecedent-consequent models of explanation undermines the study of persons. New Ideas in Psychology, 44, 14-20. https://doi.org/10.1016/j.newideapsych.2016.11.009 